2 Meltzer E, Steinlauf S. The clinical manifestations of lithium intoxication. Isr Med Assoc J 2002;4:265-7

3 Nagappan R, Parkin WG, Holdsworth SR. Acute lithium intoxication Anaesth Intensive Care 2002;30:90-2

4 Oakley PW, Whyte IM, Carter GL. Lithium toxicity: an iatrogenic problem in susceptible individuals. Aust N Z J Psychiatry 2001;35:833-40

5 Fenves AZ, Emmett M, White MG. Lithium intoxication associated with acute renal failure. South Med J 1984;77:1472-4

\section{Anticoagulation in a head-injured patient}

\author{
Ahmed Ibrahim MBBS MRCS \\ Keyoumars Ashkan MRCP FRCS \\ Martin Smith MBBS FRCA \\ Lawrence Watkins MA FRCS
}

J R Soc Med 2003;96:591-592

The use of low-molecular-weight heparin in neurosurgical patients is controversial.

\section{CASE HISTORY}

A man of 53 sustained a small frontal contusion in a fall (Figure 1). Initially, he was fully alert and oriented and he was admitted for observation to the local hospital. There was no relevant medical history, and blood results including a clotting screen were normal. A week later he became acutely breathless and was found to have a $\mathrm{PaO}_{2}$ of $9 \mathrm{kPa}$ and raised D-dimers. A pulmonary embolus was suspected and he was started on enoxaparin $120 \mathrm{mg}$ once a day. Within a few hours of receiving the first dose of this lowmolecular-weight heparin the patient's level of consciousness began to deteriorate. He was opening his eyes, making incomprehensible sounds and flexing his limbs to painful stimuli (Glasgow coma score 9). A repeat head scan revealed considerable progression of the frontal contusion (Figure 2). After intubation he was transferred to our unit, and on arrival his activated partial thromboplastin time (APTT) was 67 seconds (normal range 22-41). He was managed conservatively in the intensive care unit; an intracranial pressure monitor was not inserted for fear of inducing further haemorrhage. The next day spiral CT of the chest showed no evidence of pulmonary embolus. The

Departments of Neurosurgery and Neuroanaesthesia, National Hospital for Neurology and Neurosurgery, London, UK

Correspondence to: Dr Ahmed Ibrahim, 38 C Camden Road, London NW1 9DR, UK

E-mail: aibrahim@doctors.net.uk
APTT gradually improved and was normal within four days. Thereafter he made a good recovery.

\section{COMMENT}

In patients already receiving anticoagulants, the special hazards of head injury are well known. In a retrospective study the case fatality was 50\% compared with $20 \%$ in a group not receiving anticoagulants. ${ }^{1}$ The question of thromboembolism prophylaxis in neurosurgical patients is difficult: these patients are commonly immobile for long periods and are prone to deep vein thrombosis, yet haemorrhage into the operation site is more dangerous than in other forms of surgery where heparin prophylaxis is advocated. Nurmohamed and co-workers ${ }^{2}$ used fractionated or low-molecular-weight heparin in addition to compression stockings postoperatively in neurosurgical patients and reported a clinically significant decrease in venous thromboembolism without increased risk of major bleeding, and Constantini et al. ${ }^{3}$ found no excess risk from perioperative low-molecular-weight heparin, in a randomized comparison with $0.9 \%$ saline, in patients having brain surgery. These studies were in elective neurosurgery. In emergency work, Norwood and colleagues ${ }^{4}$ gave enoxaparin, $30 \mathrm{mg}$ 12-hourly, to 177 patients admitted with blunt injury and with documented intracranial haemorrhage. Progression of intracranial haemorrhage, on CT, was seen in $4 \%$ and the authors concluded that enoxaparin could

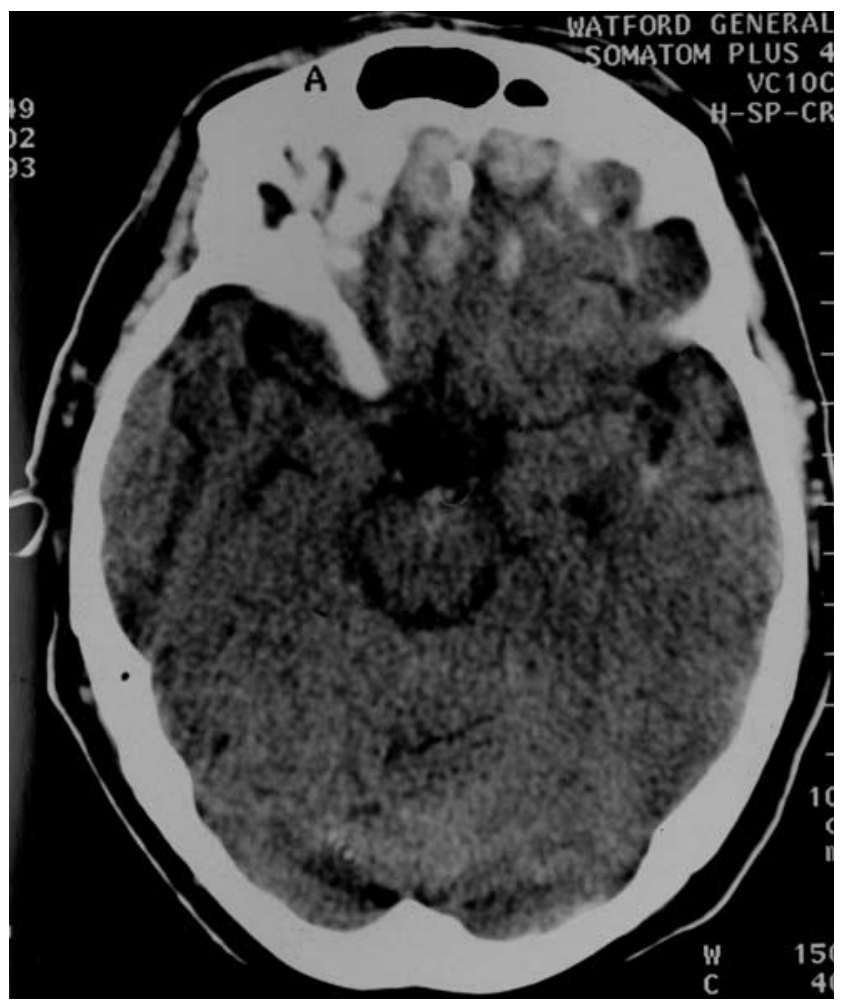

Figure $1 \mathbf{C T}$ brain scan showing bifrontal contusions 


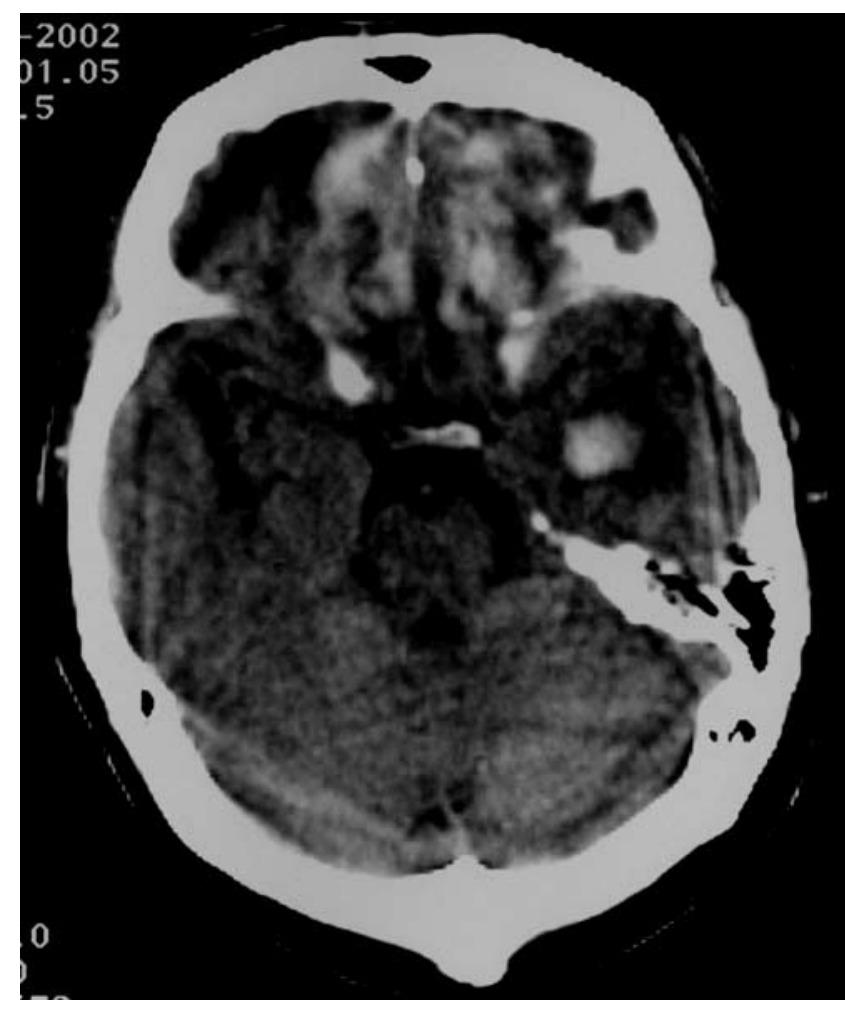

Figure 2 CT scan showing worsening of bifrontal haemorrhage

be used for prophylaxis if started 24 hours or more after the acute admission.

In the case described here, cerebral haemorrhage worsened when a low-molecular-weight heparin was given a week after the original injury -and there were no apparent aggravating factors such as clotting derangements or sepsis. Although the aim was therapeutic rather than prophylactic (pulmonary embolism was suspected), the case does illustrate the hazards of these agents. Most of the published evidence on anticoagulation in headinjured patients is retrospective and thus insecure. For prophylaxis at least, until better evidence emerges, we would favour mechanical measures (antiembolism stockings, intermittent calf compression, physiotherapy) rather than heparins.

\section{REFERENCES}

1 Karni A, Holtzman R, Bass $T$, et al. Traumatic head injury in the anticoagulated elderly patients: a lethal combination. Am Surg 2001;67: 1098-100

2 Nurmohamed MT, Van Riel AM, Henkens CM. Low molecular weight heparin and compression stockings in the prevention of venous thromboembolism in neurosurgery. Thrombosis Haemostasis 1996;75: 233-8

3 Constantini S, Kaner A, Friedman A, et al. Study of perioperative minidose heparin in patients undergoing brain tumour surgery: a prospective, randomised, double blind study. J Neurosurg 2001;94: 918-21

4 Norwood SH, McAuley CE, Berne JD, et al. Prospective evaluation of enoxaparin prophylactics for venous thrombo-embolism in patients with intracranial hemorrhagic injuries. Arch Surg 2002;137: 696-701

\section{Atypical melanoma}

\author{
Susannah Baron ChB MRCP \\ Victoria Goulden MD FRCP Graeme Stables MD FRCP
}

The incidence of malignant melanoma continues to rise in many parts of the world. A seven-point checklist for moles is useful in identifying lesions that need to be excised. The three major signs are change in shape, change in size and change in colour; the four minor signs are over $7 \mathrm{~mm}$ in diameter, inflammation, crusting or bleeding and minor irritation or itch. Lesions with any major signs or three minor signs are suspicious of melanoma. ${ }^{1}$ Unfortunately malignant melanoma can present atypically.

\section{CASE HISTORIES}

\section{Case 1}

A woman of 40 sought advice about an erythematous scaly plaque on her left arm, $0.6 \times 0.4 \mathrm{~cm}$, which had appeared 3 years earlier (Figure 1). The lesion had gradually increased in size and become more erythematous over the preceding three months. She had experienced blistering sunburn in childhood but there was no family history of skin cancer. The differential diagnosis was Bowen's disease (intraepithelial carcinoma) or an irritated seborrhoeic wart, but a punch biopsy showed in-situ melanoma. The melanoma was excised with a $5 \mathrm{~mm}$ margin and histological examination confirmed lack of dermal invasion. The patient was apparently disease-free twelve months later.

\section{CASE 2}

A woman aged 79 had first noticed the lesion on her cheek 2 years before, after a minor trauma. It had gradually enlarged. On examination she had an infiltrated plaque with a pearly edge; the diameter was about $3.3 \mathrm{~cm}$ but the edges were indistinct. Directly below her eye were two pigmented macules and there were several pigmented nodules within the plaque (Figure 2). The clinical diagnosis was a pigmented basal cell carcinoma but urgent biopsy revealed the lesion to be a superficial spreading malignant melanoma with both vertical and horizontal growth phases. The maximum thickness of the tumour on biopsy was $4.2 \mathrm{~mm}$. The melanoma was widely excised by the plastic surgeons and the area was reconstructed with a skin graft. On histological examination the Breslow thickness was

General Infirmary at Leeds, LS1 3EX, UK

Correspondence to: Dr S Baron

E-mail: Susannah.baron@ntlworld.com 